\title{
Skin Mucus Fatty Acid Composition of Gilthead Sea Bream (Sparus Aurata): A Descriptive Study in Fish Fed Low and High Fish Meal Diets
}

\author{
Silvia Torrecillas* $*$, Daniel Montero, David Domínguez ${ }^{\mathbb{D}}$, Lidia Robaina and Marisol Izquierdo \\ Grupo de Investigación en Acuicultura (GIA), IU-ECOAQUA, Universidad de Las Palmas de Gran Canaria, \\ Crta. Taliarte s/n, Telde, 35214 Las Palmas, Canary Islands, Spain; daniel.montero@uplpgc.es (D.M.); \\ david.dominguez103@alu.ulpgc.es (D.D.); lidia.robaina@ulpgc.es (L.R.); marisol.izquierdo@ulpgc.es (M.I.) \\ * Correspondence: silvia.torrecillas@giaqua.org; Tel./Fax: +34-626715903
}

Received: 19 December 2018; Accepted: 18 February 2019; Published: 27 February 2019

\begin{abstract}
Terrestrial protein and lipid sources are commonly used as substitutes for marine fishery-derived raw ingredients in fish diets. However, their use is related with several side-effects on marine fish performance, health, or disease resistance. Physical barriers of the skin, gills, and gut constitute the primary defense mechanism of fish. Skin mucus mucosal mucins, water, proteins, ions, and lipids determine the physical, chemical, and protective characteristics of skin mucus. Very little is known about the influence of diet composition on fish skin mucus fatty acid profile. Gilthead sea bream skin mucus contained $10 \%$ of total lipids (TL), which consisted of 50-60\% neutral (NL) and $40-50 \%$ polar lipids (PL) fractions. $\Sigma \mathrm{n}-3$ long chain polyunsaturated fatty acids (LC-PUFA) deposition was preferential in the NL fraction, whereas $\Sigma \mathrm{n}-6$ LC-PUFA accumulation was similar in both lipid classes. Docosahexaenoic acid (DHA; 22:6n-3) was the main LC-PUFA stored in skin mucus $(14 \% \mathrm{TL})$ in relation to eicosapentaenoic acid (EPA; $20: 5 \mathrm{n}-3)(2-3 \% \mathrm{TL})$ and arachidonic acid (ARA; 20:4n-6) (2\% TL). This study denotes the importance of DHA as component of skin mucus lipids compared to other essential fatty acids, such as EPA and ARA, as well as importance of maintaining an adequate $\Sigma n-3 / \Sigma n-6$ ratio, regardless of dietary intake.
\end{abstract}

Keywords: Skin mucus; fatty acid profile; fishmeal; vegetable meal; Sparus aurata

\section{Introduction}

Terrestrial protein and lipid sources are commonly used as substitutes to marine fishery-derived proteins and lipids in gilthead sea bream (Sparus aurata) commercial diets [1-3]. However, even when diets are formulated to cover the theoretical nutrient requirements for essential fatty acids or amino acids [4], variations in their dietary percentage, and thus in specific ratios among them, have been related with several side-effects on marine fish growth performance, health, welfare, or disease resistance. Furthermore, high levels of dietary plant protein sources may negatively affect the bioavailability of micronutrients [5], contain endogenous anti-nutritional factors, and alter fatty acid profiles, affecting not only fish growth but also fish health and disease resistance [6-9].

Physical barriers of the skin, gills, and gut constitute the primary defense mechanism of fish exposed to an external infectious or damaging agent [10]. Fish skin shares common components with mammalian mucosal surfaces, such as the presence of macrophages, lymphocytes, eosinophilic granulocytes, dendritic cells, an organized cytokine response, and scattered mucus-secreting cells in the epithelium [11], particularly in the stratum spinosum. Skin mucus acts as a physical, semipermeable, dynamic, chemical, and biological barrier $[12,13]$. The physical, chemical, and protective characteristics of mucus are determined by its composition, which is mainly based on water, mucosal mucins, 
and a mixture of proteins, ions, and lipids [11]. The influence of water bacterial load or parasite presence on the composition and physicochemical properties of skin mucus has been described through recognition of pathogen-associated molecular patterns (PAMPs) [14-16]. In higher vertebrates, it has been demonstrated that skin lipid film can be modulated through the diet more efficiently than, for example, through direct topical application [17]. However, in fish, very little is known about the effects of high dietary levels of plant meals and oils on the composition and particularly on the fatty acid profiles of skin mucus - this represents the main objective of this study for gilthead sea bream (Sparus aurata), one of the most cultivated species in the Mediterranean.

\section{Results}

No differences in final weight were found between fish fed H-FM (High-Fish meal; 63\% FM; $254.8 \pm 8.9 \mathrm{~g})$ and L-FM (Low-Fish meal; 15\% FM; $227.1 \pm 19.7 \mathrm{~g})$ diets $(\mathrm{t}=-1.959 ; p=0.053)$. In general, gilthead sea bream skin mucus consists of $10 \%$ total lipids (TL) on a dry weight basis (Table 1). The neutral lipid (NL) and polar lipid (PL) fractions of skin mucus represented around $50-60 \%$ and $40-50 \%$ respectively, in contrast to the dietary lipid percentages ( $80-90 \% \mathrm{NL}, 10-20 \% \mathrm{PL}$ ). A trend to higher PL and lower NL proportions was observed in the skin mucus of fish fed the H-FM diet (Table 1).

Table 1. Lipid content and fatty acid composition (\% of total identified fatty acids) of gilthead sea bream (Sparus aurata) skin mucus total lipids, neutral, and polar fractions.

\begin{tabular}{|c|c|c|c|c|c|c|}
\hline & \multicolumn{6}{|c|}{ Skin Mucus } \\
\hline & \multicolumn{2}{|c|}{ Total Lipids (\%) } & \multicolumn{2}{|c|}{ Neutral Lipids (\% of TL) } & \multicolumn{2}{|c|}{ Polar Lipids ( $\%$ of TL $\%$ ) } \\
\hline & L-FM & H-FM & L-FM & H-FM & L-FM & H-FM \\
\hline & 10.3 & 11.5 & 60.0 & 53.2 & 40.0 & 46.8 \\
\hline \multicolumn{7}{|l|}{ Fatty Acid } \\
\hline 14:0 & $1.4 \pm 0.2$ & $1.8 \pm 0.1$ & $1.4 \pm 0.2$ & $1.1 \pm 0.2$ & $1.6 \pm 0.2$ & $1.5 \pm 0.1$ \\
\hline $15: 0$ & $0.2 \pm 0.0$ & $0.3 \pm 0.0$ & $0.3 \pm 0.0$ & $0.3 \pm 0.0$ & $0.3 \pm 0.0$ & $0.3 \pm 0.0$ \\
\hline 16:0ISO & $0.4 \pm 0.1$ & $0.4 \pm 0.1$ & $0.2 \pm 0.1$ & $0.5 \pm 0.1$ & $0.6 \pm 0.1$ & $0.9 \pm 0.2$ \\
\hline $16: 0$ & $21.8 \pm 0.1$ & $20.1 \pm 0.1$ & $17.6 \pm 0.2$ & $23.9 \pm 0.2$ & $33.5 \pm 0.2$ & $30.4 \pm 0.1$ \\
\hline $16: 1 n-7$ & $2.2 \pm 0.0$ & $3.0 \pm 0.0$ & $2.8 \pm 0.0$ & $1.9 \pm 0.0$ & $0.9 \pm 0.0$ & $1.3 \pm 0.0$ \\
\hline $17: 0$ & $0.1 \pm 0.0$ & $0.1 \pm 0.0$ & $0.2 \pm 0.0$ & $0.1 \pm 0.0$ & $0.1 \pm 0.0$ & $0.1 \pm 0.0$ \\
\hline $16: 3 n-4$ & $0.2 \pm 0.0$ & $0.2 \pm 0.0$ & $0.2 \pm 0.0$ & $0.2 \pm 0.0$ & $0.1 \pm 0.0$ & $0.1 \pm 0.0$ \\
\hline $16: 3 n-1$ & $2.5 \pm 0.0$ & $1.9 \pm 0.0$ & $1.4 \pm 0.0$ & $2.9 \pm 0.0$ & $4.5 \pm 0.0$ & $4.0 \pm 0.0$ \\
\hline $16: 4 n-3$ & $2.4 \pm 0.0$ & $1.9 \pm 0.0$ & $1.7 \pm 0.1$ & $2.7 \pm 0.0$ & $3.7 \pm 0.0$ & $3.5 \pm 0.0$ \\
\hline $16: 4 n-1$ & $0.3 \pm 0.0$ & $0.3 \pm 0.0$ & $0.2 \pm 0.0$ & $0.4 \pm 0.0$ & $0.5 \pm 0.0$ & $0.6 \pm 0.0$ \\
\hline $18: 0$ & $6.6 \pm 0.1$ & $5.7 \pm 0.1$ & $4.1 \pm 0.3$ & $7.5 \pm 0.2$ & $13.0 \pm 0.1$ & $11.3 \pm 0.3$ \\
\hline $18: 1 n-9$ & $22.5 \pm 0.2$ & $22.7 \pm 0.2$ & $27.1 \pm 0.8$ & $21.7 \pm 0.5$ & $11.9 \pm 0.5$ & $11.9 \pm 0.4$ \\
\hline $18: 1 n-7$ & $2.2 \pm 0.0$ & $2.4 \pm 0.0$ & $2.3 \pm 0.1$ & $2.4 \pm 0.1$ & $2.0 \pm 0.1$ & $2.0 \pm 0.1$ \\
\hline $18: 2 n-9$ & $0.6 \pm 0.0$ & $0.3 \pm 0.0$ & $0.7 \pm 0.0$ & $0.7 \pm 0.0$ & $0.2 \pm 0.0$ & $0.1 \pm 0.0$ \\
\hline $18: 2 n-6$ & $11.0 \pm 0.1$ & $10.1 \pm 0.1$ & $13.8 \pm 0.3$ & $11.5 \pm 0.1$ & $4.8 \pm 0.2$ & $4.7 \pm 0.2$ \\
\hline $18: 3 n-6$ & $0.5 \pm 0.0$ & $0.3 \pm 0.0$ & $0.5 \pm 0.0$ & $0.5 \pm 0.0$ & $0.4 \pm 0.0$ & $0.3 \pm 0.0$ \\
\hline $18: 3 n-3$ & $0.9 \pm 0.0$ & $1.3 \pm 0.0$ & $1.1 \pm 0.2$ & $0.5 \pm 0.2$ & $0.2 \pm 0.1$ & $0.3 \pm 0.2$ \\
\hline $18: 4 n-3$ & $0.3 \pm 0.0$ & $0.5 \pm 0.0$ & $0.4 \pm 0.1$ & $0.3 \pm 0.0$ & $0.2 \pm 0.1$ & $0.2 \pm 0.1$ \\
\hline $18: 4 n-1$ & $0.1 \pm 0.0$ & $0.0 \pm 0.0$ & $0.1 \pm 0.0$ & $0.1 \pm 0.0$ & $0.2 \pm 0.0$ & $0.1 \pm 0.0$ \\
\hline 20:0 & $0.3 \pm 0.0$ & $0.3 \pm 0.0$ & $0.2 \pm 0.0$ & $0.4 \pm 0.0$ & $0.7 \pm 0.0$ & $0.6 \pm 0.0$ \\
\hline $20: 1 n-9$ & $0.3 \pm 0.0$ & $0.3 \pm 0.0$ & $0.3 \pm 0.0$ & $0.3 \pm 0.0$ & $0.2 \pm 0.0$ & $0.2 \pm 0.0$ \\
\hline $20: 1 n-7$ & $1.1 \pm 0.2$ & $1.4 \pm 0.1$ & $1.2 \pm 0.1$ & $0.8 \pm 0.1$ & $0.7 \pm 0.1$ & $0.7 \pm 0.1$ \\
\hline $20: 1 n-5$ & $0.2 \pm 0.0$ & $0.2 \pm 0.0$ & $0.1 \pm 0.0$ & $0.2 \pm 0.0$ & $0.2 \pm 0.0$ & $0.2 \pm 0.0$ \\
\hline $20: 2 n-9$ & $0.2 \pm 0.0$ & $0.2 \pm 0.0$ & $0.2 \pm 0.0$ & $0.2 \pm 0.0$ & $0.1 \pm 0.0$ & $0.1 \pm 0.0$ \\
\hline $20: 2 n-6$ & $0.5 \pm 0.0$ & $0.4 \pm 0.0$ & $0.5 \pm 0.1$ & $0.6 \pm 0.0$ & $0.4 \pm 0.0$ & $0.4 \pm 0.0$ \\
\hline $20: 3 n-6$ & $0.5 \pm 0.0$ & $0.3 \pm 0.0$ & $0.5 \pm 0.0$ & $0.5 \pm 0.0$ & $0.3 \pm 0.0$ & $0.2 \pm 0.0$ \\
\hline $20: 4 n-6$ & $2.0 \pm 0.1$ & $2.1 \pm 0.1$ & $1.7 \pm 0.0$ & $1.6 \pm 0.0$ & $2.5 \pm 0.0$ & $3.0 \pm 0.0$ \\
\hline $20: 3 n-3$ & $0.1 \pm 0.0$ & $0.1 \pm 0.0$ & $0.1 \pm 0.0$ & $0.1 \pm 0.0$ & $0.1 \pm 0.0$ & $0.1 \pm 0.0$ \\
\hline
\end{tabular}


Table 1. Cont.

\begin{tabular}{|c|c|c|c|c|c|c|}
\hline & \multicolumn{6}{|c|}{ Skin Mucus } \\
\hline & \multicolumn{2}{|c|}{ Total Lipids (\%) } & \multicolumn{2}{|c|}{ Neutral Lipids (\% of TL) } & \multicolumn{2}{|c|}{ Polar Lipids (\% of TL \%) } \\
\hline & L-FM & H-FM & L-FM & H-FM & L-FM & H-FM \\
\hline & 10.3 & 11.5 & 60.0 & 53.2 & 40.0 & 46.8 \\
\hline $20: 4 n-3$ & $0.2 \pm 0.0$ & $0.3 \pm 0.0$ & $0.3 \pm 0.0$ & $0.1 \pm 0.0$ & $0.1 \pm 0.1$ & $0.1 \pm 0.0$ \\
\hline $20: 5 n-3$ & $1.9 \pm 0.1$ & $2.8 \pm 0.1$ & $2.4 \pm 0.1$ & $1.5 \pm 0.2$ & $1.1 \pm 0.3$ & $1.8 \pm 0.3$ \\
\hline $22: 1 n-11$ & $0.5 \pm 0.5$ & $0.9 \pm 0.4$ & $0.7 \pm 0.0$ & $0.3 \pm 0.1$ & $0.1 \pm 0.1$ & $0.1 \pm 0.1$ \\
\hline $22: 1 n-9$ & $0.2 \pm 0.0$ & $0.3 \pm 0.0$ & $0.2 \pm 0.0$ & $0.2 \pm 0.0$ & $0.1 \pm 0.0$ & $0.1 \pm 0.0$ \\
\hline $22: 4 n-6$ & $0.2 \pm 0.0$ & $0.2 \pm 0.0$ & $0.1 \pm 0.0$ & $0.1 \pm 0.0$ & $0.2 \pm 0.0$ & $0.2 \pm 0.0$ \\
\hline $22: 5 n-6$ & $0.4 \pm 0.0$ & $0.4 \pm 0.0$ & $0.3 \pm 0.0$ & $0.3 \pm 0.0$ & $0.4 \pm 0.1$ & $0.5 \pm 0.0$ \\
\hline $22: 5 n-3$ & $1.1 \pm 0.0$ & $1.4 \pm 0.0$ & $1.2 \pm 0.1$ & $0.8 \pm 0.1$ & $0.9 \pm 0.1$ & $1.0 \pm 0.1$ \\
\hline $22: 6 n-3$ & $13.5 \pm 0.4$ & $14.4 \pm 0.5$ & $13.1 \pm 0.2$ & $12.2 \pm 0.4$ & $12.6 \pm 0.7$ & $16.6 \pm 0.5$ \\
\hline Saturated & $30.5 \pm 0.6$ & $28.4 \pm 0.4$ & $23.7 \pm 1.2$ & $33.2 \pm 0.9$ & $49.2 \pm 0.8$ & $44.3 \pm 0.7$ \\
\hline Monoenes & $29.6 \pm 1.5$ & $31.4 \pm 1.1$ & $35.0 \pm 1.6$ & $28.0 \pm 1.1$ & $16.5 \pm 1.3$ & $16.8 \pm 1.2$ \\
\hline$\Sigma \mathrm{n}-3$ & $20.5 \pm 0.8$ & $22.8 \pm 0.9$ & $20.4 \pm 1.2$ & $18.3 \pm 1.4$ & $19.0 \pm 1.9$ & $23.7 \pm 1.8$ \\
\hline$\Sigma n-6$ & $15.0 \pm 0.3$ & $13.8 \pm 0.3$ & $17.5 \pm 0.6$ & $15.3 \pm 0.3$ & $8.9 \pm 0.6$ & $9.3 \pm 0.4$ \\
\hline$\Sigma \mathbf{n}-9$ & $23.8 \pm 0.4$ & $23.7 \pm 0.3$ & $28.5 \pm 1.2$ & $23.0 \pm 0.8$ & $12.6 \pm 0.8$ & $12.4 \pm 0.7$ \\
\hline$\Sigma n-3 L C-P U F A$ & $16.8 \pm 0.7$ & $19.0 \pm 0.8$ & $17.2 \pm 0.7$ & $14.7 \pm 1.1$ & $14.8 \pm 1.6$ & $19.7 \pm 1.4$ \\
\hline $\begin{array}{c}\Sigma n-6 \\
\text { LC-PUFA }\end{array}$ & $3.0 \pm 0.2$ & $3.0 \pm 0.2$ & $2.7 \pm 0.1$ & $2.7 \pm 0.1$ & $3.4 \pm 0.2$ & $3.9 \pm 0.1$ \\
\hline$\Sigma n-3 / \Sigma n-6$ & $1.4 \pm 0.0$ & $1.6 \pm 0.0$ & $1.2 \pm 0.0$ & $1.2 \pm 0.1$ & $2.1 \pm 0.1$ & $2.6 \pm 0.1$ \\
\hline
\end{tabular}

FM: Fish meal; H-FM: High Fish meal-based diet (63\% FM); L-FM: Low-Fish meal-based diet (15\% FM); TL: Total lipids; NL: neutral Lipids; PL: Polar lipids; LC-PUFA: long chain-polyunsaturated fatty acids. Means and SD. Different letters indicate significant differences among dietary treatments (Student's t-test; $p<0.05$ ).

Regarding fatty acid profiles from total skin mucus lipids, fish fed the L-FM diet presented a similar fatty acid profile to fish fed the H-FM diet, despite the different dietary intake. Saturated fraction content increased in both dietary treatments $(t=4.304 ; p=0.057)$ when compared to dietary percentages, mainly due to an increase in 16:0 (palmitic acid) and 18:0 (estearic acid), whilst 17:0 and 20:0 deposition slightly decreased. The $\Sigma \mathrm{n}-3$ deposition increased in the skin mucus of fish fed the L-FM diet $(18.5 \%)$, reaching similar levels $(t=-2.677 ; p=0.116)$ to that of fish fed the H-FM diet $(20.0 \%)$, mainly due to a higher percentage of $16: 4 \mathrm{n}-3(\mathrm{t}=23.931 ; \mathrm{p}=0.02)$, docosapentaenoic acid $($ DPA; 22:5n-3; $\mathrm{t}=-11.901 ; p=0.07)$, and eicosapentaenoic acid (EPA; 20:5n-3; $\mathrm{t}=-7.069 ; p=0.019$ ). The $\Sigma \mathrm{n}-6$ fatty acid levels reflected mainly those of the diet, although a general trend to a greater proportion of $18: 3 n-6,20: 3 n-6$, ARA, $22: 4 n-6$, and 22:5n-6 can be observed, which was especially evident in fish fed the L-FM diet. The $\Sigma \mathrm{n}-3$ LC-PUFA $(\mathrm{t}=-2.930 ; p=0.099)$ and $\Sigma \mathrm{n}-6$ LC-PUFA $(t=0.262 ; p=0.818)$ fractions are highly incorporated in the total lipids of the skin mucus of gilthead sea bream fed both diets, however this effect was highly marked in fish fed the L-FM diet, mainly as a consequence of a higher incorporation of DPA, DHA, 20:3n-6, ARA, 22:4n-6, and 22:5n-6 in relation to dietary intake. Despite this selective incorporation in fish fed L-FM diet it was not enough to reach the $\Sigma \mathrm{n}-3 / \Sigma \mathrm{n}-6$ ratio of skin mucus total lipids of fish fed H-FM diet $(\mathrm{t}=-10.036 ; p=0.010)$.

Regarding the fatty acids from the neutral fraction of skin mucus, the highest saturated $(t=-9.036$; $p=0.011)$ and lowest monoenoic $(t=5.028 ; p=0.037)$ fatty acid percentages were observed in fish fed the H-FM diet compared to fish fed the L-FM diet, mainly due to a greater incorporation of 16:0 and 18:0 and lower content of 18:1n-9 and 22:1n-11, respectively (Table 1). In contrast, and in relation to dietary intake (skin mucus/diet ratio). NL skin mucus $\Sigma \mathrm{n}-3(\mathrm{t}=4.112 ; p=0.05)$ and $\Sigma \mathrm{n}-3 \mathrm{LC}$-PUFA $(\mathrm{t}=8.445 ; p=0.015)$ deposition was greater in fish fed the L-FM diet than in fish fed the H-FM diet ( $1.5 \pm 0.1$ vs $1.1 \pm 0.1$ and $2.26 \pm 0.1$ vs $1.41 \pm 0.1$, respectively), mostly due to a higher incorporation of 20:4n-3, EPA, DPA, and DHA in relation to dietary intake. NL skin mucus $\Sigma \mathrm{n}-6$ and $\Sigma \mathrm{n}-6$ LC-PUFA content presented a selective accumulation of 20:3n-6, ARA, 22:4n-6, and 22:5n-6 in relation to dietary fatty acids content, resulting in a similar $\Sigma n-3 / \Sigma n-6$ ratio for the skin mucus of fish fed both 
dietary treatments $(\mathrm{t}=-0.667 ; p=0.573)$. Indeed, the $\Sigma \mathrm{n}-6 \mathrm{LC}-\mathrm{PUFA}$ skin mucus/diet ratio accounted for $6.8 \pm 0.2$ and $5.3 \pm 0.2$ in fish fed the L-FM diet and H-FM diet $(\mathrm{t}=-6.600 ; p=0.022)$, respectively.

Regarding the fatty acids from the skin mucus PL fraction, and contrary to the NL fraction, fish fed the L-FM diet presented the highest saturated fraction $(\mathrm{t}=-6.324 ; p=0.024)$ content (predominantly palmitic acid and stearic acid). In the case of $\Sigma n-3$ and $\Sigma n-3 L C-P U F A$ deposition, despite 20:4n-3, EPA, DPA, and DHA being better incorporated in the skin mucus PL fraction of fish fed the L-FM diet, the increased mucus/diet fatty acid ratio was not enough to reach H-FM-fed fish percentages $\left(\mathrm{t}_{\Sigma \mathrm{n}-3}=-2.534 ; p=0.127\right.$ and $\left.\mathrm{t}_{\Sigma \mathrm{n}-3 \mathrm{LC}-\mathrm{PUFA}}=-3.252 ; p=0.084\right)$. On the contrary, for fish fed the L-FM diet, the high incorporation of linoleic acid (18:2n-6; LA), 20:3n-6, and ARA resulted in a similar $\Sigma \mathrm{n}-6(\mathrm{t}=-0.659 ; p=0.578)$ and $\Sigma \mathrm{n}-6 \mathrm{LC}-\mathrm{PUFA}(\mathrm{t}=-3.822 ; p=0.062)$ content for the PL skin mucus of fish fed both diets, altogether resulting in a $\Sigma n-3 / \Sigma n-6$ ratio for L-FM and the H-FM diets of 2.1 and 2.6, respectively, which still differed among treatments $(t=-5.526 ; p=0.031)$.

When comparing between both lipid fractions, PL presented higher proportions of saturated $(\mathrm{t}=-5.803 ; p=0.001)$ fatty acids and a lower content of monoenoics $(\mathrm{t}=6.828 ; p=0.001), \Sigma \mathrm{n}-6$ $(\mathrm{t}=10.165 ; p=0.001)$, and $\Sigma \mathrm{n}-9(\mathrm{t}=7.953 ; p=0.001)$ than NL due to its structural characteristics, resulting in an almost two-fold greater $\Sigma \mathrm{n}-3 / \Sigma \mathrm{n}-6$ ratio $(\mathrm{t}=-8.954 ; p=-0.001)$. Additionally, $\Sigma$ n-6LC-PUFA was specifically stored in both lipid classes of gilthead sea bream skin mucus in relation to dietary content, especially due to a specific deposition of ARA and 22:5n-6. The $\Sigma$ n-3LC-PUFA was preferentially stored in NL compared to the skin mucus PL fraction (skin mucus/diet ratio of $1.8 \pm 0.5$ and $0.8 \pm 0.2$, respectively; $\mathrm{t}=3.820 ; p=0.009)$. The NL fraction reached almost a similar $\Sigma \mathrm{n}-3 L C-P U F A$ level to that presented by the PL fraction $(\mathrm{t}=-0.754 ; p=0.480)$, particularly due to a higher deposition of DHA and DPA. This resulted in a sea bream skin mucus $\Sigma \mathrm{n}-3 / \Sigma \mathrm{n}-6$ ratio of 1.2 and 2.1-2.6 $(\mathrm{t}=-8.954 ; p=0.001)$ for NL and PL, respectively.

\section{Discussion}

The physical, chemical, and protective characteristics of fish skin mucus are determined by its composition [11], however, its lipid composition and possible functions have been scarcely studied [18]. Mucus composition studies from other mucosal surfaces, such as the gut, indicate that mucus lipids are good biomarker candidates and that variations in its composition or concentrations may indicate its functional role $[18,19]$. In the present study, and regardless of diet composition, gilthead sea bream skin mucus lipid content (10-11\% dw: 0.8-1\% ww) was higher than that reported in previous studies for several fresh water fish species, such as African catfish (Clarias gariepinus; 5.9\% dw) and Malaysia catfish (Clarias sp.1; 4.0\% dw) [20], or marine species such as Seriola dumerli (0.62\% ww) [21] or Verasper variegatus (0.66\% ww) [21]. Despite the different dietary intake, the gilthead skin mucus NL fraction accounted for approximately $6.1-6.2 \%(d w)$ of the total lipid content in fish fed both diets, whereas the PL fraction represented 40\% $(4.2 \% d w)$ in fish fed L-FM-based diets and $47 \%(5.3 \% d w)$ in fish fed H-FM-based diets. These percentages represent a 4- and 2-fold increase in PL content in relation to dietary contents, respectively, and emphasize the importance of PL in fish skin lipid mucus composition. In higher vertebrates, the orientation of the PL lipophilic region, together with the nature of the fatty acids, determines the hydrophobicity of the mucus gel layer, forming a "non-wettable" resistant layer towards the external surface of fatty acid tails [22-24]. In fact, in reference [18], the authors established an interaction between the fish mucus PL and glycoprotein fractions in relation to the mucus layer viscosity, with fish mucus viscosity increasing with higher levels of mucus PL. In this sense, for example, it has been suggested that Labroides dimidiatus skin mucus PL content influences the protective role and the rigidity of the mucus layer in relation to its ability to survive in a parasitic environment [25].

The total skin mucus lipid fatty acid profiles of fish fed both dietary treatments were similar regardless of the different dietary profile. The similar percentages observed in both groups for saturated, $\Sigma \mathrm{n}-3, \Sigma \mathrm{n}-3 \mathrm{LC}-\mathrm{PUFA}$, and $\Sigma \mathrm{n}-6 \mathrm{LC}$-PUFA fractions denote the essentiality of these groups of fatty acids in gilthead sea bream mucus. Particularly, the high percentages of palmitic and stearic fatty acids present in gilthead seabream skin mucus are in accordance with previous findings in 
other fish species, such as Seriola dumerli, V. variegatus [21], L. dimidiatus [25], and Channa striatus [26], and they are probably related to its structural role in the sn1 position of PL. Unfortunately, there is no information available about the fatty acid composition of fish mucus PL. However, based on studies on higher vertebrates, phosphatidylcholine and lysophosphatidylcholine are the major species in colonic mucus [24,27], which contain typically one saturated (palmitic or stearic acids) and one unsaturated fatty acid (oleic/linoleic acids) [24]. Indeed, in the present study, palmitic and stearic fatty acid contents were specifically increased in the skin mucus PL fraction.

Furthermore, the selective incorporation of $\Sigma n-3 L C-P U F A$ and $\Sigma n-6 L C-P U F A$ fractions observed in the total lipid skin mucus of gilthead seabream is remarkable when fed a L-FM-based diet, however they differ in the fraction where they were incorporated. The $\Sigma \mathrm{n}-3 \mathrm{LC}$-PUFA fraction was preferably incorporated in the NL fraction, mainly as a consequence of selective deposition of DHA and DPA, whereas the $\Sigma \mathrm{n}-6$ LC-PUFA fraction was indistinctly incorporated in both lipid fractions, mainly due to a higher retention of 20:3n-6, ARA, 22:4n-6, and 22:5n-6. The increase in $\Sigma n-3 L C-P U F A$ percentages in the NL fraction suggests not only their importance as NL components in gilthead skin mucus, but also makes evident the incapacity of mucus and associated biota to use them as energy substrates, as described in fish tissues [28] and supported by the percentages of oleic acid detected in both lipid fractions. Additionally, a trend to higher DHA and ARA and a lower EPA deposition in the skin mucus PL fraction, regardless of the diet, may be indicative of changes in the PL species' percentages in relation to the physical and immune properties of mucus. Gilthead seabream skin mucus had a relatively high percentage of DHA $(14 \% \mathrm{TL})$ in relation to EPA (2-3\% TL) and ARA ( $2 \% \mathrm{TL})$, in agreement with previous results in other marine fish species, such as Seriola dumerli [21], which may be related with a higher amount of phosphatidylethanolamine and phosphatidylserine where it is preferentially deposited. Contrary to the present findings, in other freshwater fish species, such as haruan, the percentages of ARA in fish mucus represented about 20X DHA content, and this has been related with facilitating wound healing in this fish species [26] due to its cellular aggregation and blood clotting capacities, among others.

In conclusion, our results emphasize the importance of the PL fraction in gilthead sea bream skin mucus, irrespective of its dietary intake. Additionally, the results obtained show the importance of LC-PUFA fractions in NL and PL lipid fractions based mainly on the selective deposition found in fish fed lower LC-PUFA percentages. In particular, $\Sigma \mathrm{n}-3$ LC-PUFA (DHA and DPA) deposition has been found to be preferential in the NL fraction, whereas $\Sigma n-6$ LC-PUFA (20:3n-6, ARA, 22:4n-6, and 22:5n-6) deposition appears to be similar in both lipid classes. Due to the importance of the fish mucus skin layer in an aqueous immediate environment, further research is needed in order to understand the effects of feed composition on its protective function and how it can be modified through diet or diet additives, in terms of potentiating its protective functions.

\section{Materials and Methods}

Two diets were formulated to contain two levels of fish meal (FM) as follows: a high-FM-based diet (H-FM; 63\% FM) and a low-FM-based diet (L-FM; 15\% FM). Diets were isoenergetic and isonitrogenous and were formulated to meet all known nutritional requirements for several marine finfish [4] (Table 2). Diets were produced by BioMar (BioMar Tech-Centre, Brande, Denmark). Diet composition, proximate analysis, lipid class composition, and fatty acid profiles are shown in Tables 2 and 3, respectively. 
Table 2. Ingredients and analyzed proximate composition of the experimental diets.

\begin{tabular}{lll}
\hline Ingredients (\%) & L-FM & H-FM \\
\hline Fish meal $^{1}$ & 15 & 63 \\
Corn gluten $^{2}$ & 22 & - \\
Soya cake $^{2}$ & 20 & - \\
Soya protein concentrate $^{\text {Wheat gluten }}$ & 10 & - \\
Wheat $^{3}$ & 3.8 & - \\
Fish oil $^{3}$ & 11.73 & 20.52 \\
Rapeseed oil $^{4}$ & 7.5 & 8 \\
Microingredients $^{5}$ & 7.5 & 8 \\
Premix vitamins and minerals $^{6}$ & 1.99 & - \\
\hline Proximate Composition (\%) $^{6}$ & 0.45 & 0.45 \\
\hline Moisture & & \\
Crude protein & 8.08 & 7.00 \\
Crude lipids & 44.19 & 45.01 \\
Ash & 19.63 & 23.61 \\
\hline
\end{tabular}

${ }^{1}$ South-American, Superprime. ${ }^{2} 48$ Hi Pro Solvent Extract. ${ }^{3}$ STD $18 .{ }^{4}$ European, non-GM, double-low quality rapeseed oil. ${ }^{5}$ Contains monocalcium phosphate, lysine, and methionine. ${ }^{6}$ Contains vitamins and minerals to satisfy known nutritional requirements, excluding the target minerals ( $\mathrm{Zn}, \mathrm{Mn}$ and Se) (DSM Nutritional Products, Basel, Switzerland). H-FM: High Fish meal-based diet (63\%); L-FM: Low-Fish meal-based diet (15\%).

Table 3. Lipid content and fatty acid composition (\% of total identified fatty acids) of the experimental diets' total lipids, neutral, and polar fractions.

\begin{tabular}{|c|c|c|c|c|c|c|}
\hline & \multicolumn{6}{|c|}{ Experimental Diets } \\
\hline & \multicolumn{2}{|c|}{ Total Lipids (\%) } & \multicolumn{2}{|c|}{ Neutral Lipids (\% of TL) } & \multicolumn{2}{|c|}{ Polar Lipids (\% of TL \%) } \\
\hline & L-FM & H-FM & L-FM & H-FM & L-FM & H-FM \\
\hline & 19.6 & 23.6 & 90.6 & 80.4 & 9.4 & 19.6 \\
\hline \multicolumn{7}{|l|}{ Fatty Acid } \\
\hline 14:0 & 2.6 & 3.5 & 3.1 & 4.1 & 1.5 & 2.6 \\
\hline $15: 0$ & 0.2 & 0.3 & 0.3 & 0.4 & 0.3 & 0.6 \\
\hline $15: 1 n-5$ & 0.0 & 0.0 & 0.0 & 0.0 & 0.0 & 0.0 \\
\hline 16:0ISO & 0.0 & 0.1 & 0.1 & 0.1 & 0.1 & 0.1 \\
\hline $16: 0$ & 10.8 & 11.9 & 11.2 & 12.5 & 21.9 & 29.6 \\
\hline $16: 1 n-7$ & 3.0 & 4.0 & 3.2 & 4.4 & 1.6 & 2.6 \\
\hline $17: 0$ & 0.2 & 0.4 & 0.2 & 0.4 & 0.1 & 0.2 \\
\hline $16: 3 n-4$ & 0.2 & 0.1 & 0.2 & 0.4 & 0.1 & 0.1 \\
\hline $16: 3 n-1$ & 0.0 & 0.1 & 0.1 & 0.1 & 0.1 & 0.2 \\
\hline $16: 4 n-3$ & 0.3 & 0.6 & 0.0 & 0.0 & 0.0 & 0.1 \\
\hline $16: 4 n-1$ & 0.0 & 0.0 & 0.3 & 0.5 & 0.1 & 0.1 \\
\hline 18:0 & 2.7 & 3.0 & 2.8 & 3.1 & 4.9 & 8.1 \\
\hline $18: 1 n-9$ & 29.2 & 25.0 & 30.7 & 27.4 & 13.8 & 10.5 \\
\hline $18: 1 n-7$ & 2.5 & 2.7 & 2.5 & 2.8 & 2.5 & 3.6 \\
\hline $18: 2 n-9$ & 0.0 & 0.1 & 0.0 & 0.0 & 0.0 & 0.1 \\
\hline $18: 2 n-6$ & 18.2 & 14.1 & 19.5 & 14.7 & 30.2 & 5.9 \\
\hline $18: 3 n-6$ & 0.1 & 0.2 & 0.1 & 0.1 & 0.1 & 0.2 \\
\hline $18: 3 n-3$ & 4.4 & 3.9 & 4.7 & 4.0 & 2.6 & 0.6 \\
\hline $18: 4 n-3$ & 1.2 & 1.4 & 1.1 & 1.3 & 0.3 & 0.3 \\
\hline $18: 4 n-1$ & 0.1 & 0.1 & 0.1 & 0.2 & 0.2 & 0.2 \\
\hline 20:0 & 0.5 & 0.4 & 0.5 & 0.5 & 0.3 & 0.3 \\
\hline $20: 1 n-9$ & 0.2 & 0.2 & 0.2 & 0.2 & 0.1 & 0.1 \\
\hline $20: 1 n-7$ & 4.5 & 4.2 & 4.5 & 4.6 & 1.0 & 0.6 \\
\hline $20: 1 n-5$ & 0.2 & 0.2 & 0.2 & 0.3 & 0.1 & 0.2 \\
\hline $20: 2 n-9$ & 0.0 & 0.1 & 0.0 & 0.1 & 0.0 & 0.0 \\
\hline $20: 2 n-6$ & 0.2 & 0.2 & 0.2 & 0.2 & 0.1 & 0.1 \\
\hline $20: 3 n-6$ & 0.1 & 0.1 & 0.0 & 0.1 & 0.1 & 0.1 \\
\hline
\end{tabular}


Table 3. Cont.

\begin{tabular}{|c|c|c|c|c|c|c|}
\hline & \multicolumn{6}{|c|}{ Experimental Diets } \\
\hline & \multicolumn{2}{|c|}{ Total Lipids (\%) } & \multicolumn{2}{|c|}{ Neutral Lipids (\% of TL) } & \multicolumn{2}{|c|}{ Polar Lipids (\% of TL \%) } \\
\hline & L-FM & H-FM & L-FM & H-FM & L-FM & H-FM \\
\hline & 19.6 & 23.6 & 90.6 & 80.4 & 9.4 & 19.6 \\
\hline $20: 4 n-6$ & 0.3 & 0.5 & 0.2 & 0.4 & 0.7 & 1.7 \\
\hline $20: 3 n-3$ & 0.1 & 0.1 & 0.1 & 0.1 & 0.1 & 0.2 \\
\hline $20: 4 n-3$ & 0.4 & 0.4 & 0.3 & 0.4 & 0.2 & 0.3 \\
\hline $20: 5 n-3$ & 4.1 & 6.4 & 3.4 & 5.0 & 3.8 & 7.2 \\
\hline $22: 1 n-11$ & 5.8 & 4.8 & 5.0 & 4.9 & 0.9 & 0.3 \\
\hline $22: 1 n-9$ & 0.7 & 0.6 & 0.6 & 0.6 & 0.2 & 0.1 \\
\hline $22: 4 n-6$ & 0.1 & 0.1 & 0.0 & 0.1 & 0.1 & 0.1 \\
\hline $22: 5 n-6$ & 0.1 & 0.2 & 0.0 & 0.0 & 0.1 & 0.1 \\
\hline $22: 5 n-3$ & 0.7 & 1.0 & 0.5 & 0.7 & 0.8 & 1.7 \\
\hline $22: 6 n-3$ & 5.3 & 7.8 & 3.4 & 4.3 & 10.2 & 20.0 \\
\hline Saturated & 17.1 & 19.4 & 18.0 & 21.0 & 29.1 & 41.4 \\
\hline Monoenes & 46.6 & 42.4 & 47.3 & 45.9 & 20.6 & 18.6 \\
\hline$\Sigma n-3$ & 16.5 & 21.7 & 13.6 & 16.0 & 18.1 & 30.5 \\
\hline$\Sigma n-6$ & 19.0 & 15.4 & 20.1 & 15.5 & 31.3 & 8.3 \\
\hline$\Sigma \mathbf{n}-9$ & 30.2 & 26.0 & 31.6 & 28.4 & 14.2 & 10.9 \\
\hline$\Sigma \mathrm{n}-3 \mathrm{LC}-\mathrm{PUFA}$ & 10.6 & 15.7 & 7.6 & 10.4 & 15.1 & 29.3 \\
\hline $\begin{array}{c}\Sigma n-6 \\
\text { LC-PUFA }\end{array}$ & 0.5 & 0.9 & 0.4 & 0.5 & 1.0 & 2.0 \\
\hline$\Sigma n-3 / \Sigma n-6$ & 0.9 & 1.4 & 0.7 & 1.0 & 0.6 & 3.7 \\
\hline
\end{tabular}

The feeding trial was carried out at the experimental facilities of the IU-ECOAQUA of the Universidad de Las Palmas de Gran Canaria (Las Palmas, Canary Islands, Spain). Gilthead sea bream juveniles, obtained from natural spawning from our own broodstock (IU-ECOAQUA), with an average initial weight and length (mean \pm SD) of $22.5 \pm 1.5 \mathrm{~g}$ and $11.7 \pm 0.4 \mathrm{~cm}$, respectively, were fed manually until apparent satiation with one of the two experimental diets for 36 weeks ( 3 times a day, 6 days a week). Tanks were in a flow-through system with filtered seawater at a natural photoperiod (12L:12D). Water-dissolved oxygen and temperature ranged between $6.5-6.9 \mathrm{ppm}$ and $20.8-24.3^{\circ} \mathrm{C}$, respectively. After the feeding period, skin mucus samples were collected from fish by scraping the dorso-lateral surface of gilthead seabream using a spatula, taking care to avoid contamination with scales. In order to obtain enough skin mucus to perform the lipid analyses, equal samples of mucus were pooled into two pools by diet ( 2 pools of 9 fish by diet; 3 fish/tank; 3 tanks/diet). Crude lipid was extracted following the method described in [29]. One of the skin mucus pools was used for quantification of total lipid fatty acid methyl esters (FAMEs), whereas the second one was used for quantification of neutral and polar fractions of the total lipids, followed by FAMEs quantification. Neutral and polar fractions of the total lipids were separated by adsorption chromatography on silica cartridges Sep-Pak®Classic (Waters, Ireland), using chloroform and chloroform/methanol (49:1; v:v) as solvent for the neutral lipid fraction, followed by the elution of the polar fraction with methanol according to [30]. Fatty acid methyl esters were obtained by transmethylation with $1 \%$ sulphuric acid in methanol, as described in [31], and separated by gas chromatography (GC-14A, Shimadzu, Japan) in a Supercolovax-10-fused silica capillary column (Supelco, Bellefonte, USA) using helium as carrier gas, following the conditions described in [32]. Fatty acid methyl esters were quantified by a flame ionizator detector and identified by comparison with external and well-characterized fish oil standards (EPA 28, Nippai, Ltd Tokyo, Japan). Fish final weight data was tested for normality and homogeneity of variance and a Student's t-test was used to determine significant differences between fish fed the 
H-FM and L-FM diets after 36 weeks of feeding. Analyses were performed using the SPSS Statistical Software System v21.0 (SPSS, Chicago, IL, USA).

Author Contributions: S.T., D.M., L.R., and M.I. designed and supervised the study. S.T. and D.D. performed the sampling. S.T. performed analyses, processed the raw data, and wrote the manuscript with input from D.M., D.D., L.R., and M.I., D.M. and M.I. provided expertise in statistical analyses and interpretation of collected data. All authors have read, revised, and approved the final version of the manuscript.

Funding: This research was funded under the European Union's Seventh Framework Program (FP7/2001-2013) by the ARRAINA project (N288925): Advanced Research Initiatives for Nutrition and Aquaculture. The views expressed in this work are the sole responsibility of the authors and do not necessarily reflect the views of the European Commission. Complementary funding for ST was obtained through the Program Juan de la Cierva-incorporación of the Ministerio de Economía y Competitividad from the Spanish Government and to the predoctoral program of the Agencia Canaria de Investigación, Innovación y Sociedad de la información for DD.

Conflicts of Interest: The animal experiments described comply with the guidelines of the European Union Council (2010/63/EU) for the use of experimental animals and have been approved by the Bioethical Committee of the University of Las Palmas de Gran Canaria. The authors declare no conflict of interest.

$\begin{array}{ll}\text { Abbreviations } \\ \text { TL } & \text { Total lipids } \\ \text { NL } & \text { Neutral lipids } \\ \text { PL } & \text { Polar lipids } \\ \text { LC-PUFA } & \text { long chain polyunsaturated fatty acids } \\ \text { EPA } & \text { eicosapentaenoic acid }(20: 5 n-3) . \\ \text { DHA } & \text { docosahexaenoic acid }(22: 6 n-3) \\ \text { DPA } & \text { docosapentaenoic acid }(22: 5 n-3) \\ \text { ARA } & \text { arachidonic acid (20:4n-6) } \\ \text { PAMPs } & \text { pathogen-associated molecular patterns } \\ \text { FM } & \text { Fish meal } \\ \text { H-FM } & \text { High-Fish meal } \\ \text { L-FM } & \text { Low-Fish meal } \\ \text { FAMEs } & \text { fatty acid methyl esters } \\ \text { SSLs } & \text { skin surface lipids }\end{array}$

\section{References}

1. Gómez-Requeni, P.; Mingarro, M.; Calduch-Giner, J.A.; Médale, F.; Martin SA, M.; Houlihan, D.F.; Kaushik, S.; Pérez-Sánchez, J. Protein growth performance, amino acid utilization and somatotropic axis responsiveness to fish meal replacement by plant protein sources in gilthead sea bream (Sparus aurata). Aquaculture 2004, 232, 493-510. [CrossRef]

2. Izquierdo, M.; Montero, D.; Robaina, L.; Caballero, M.J.; Rosenlund, G.; Ginés, R.; Izquierdo, M. Alterations in fillet fatty acid profile and flesh quality in gilthead seabream (Sparus aurata) fed vegetable oils for a long-term period. Recovery of fatty acid profiles by fish oil feeding. Aquaculture 2005, 250, 431-444. [CrossRef]

3. Benedito-Palos, L.; Saera-Vila, A.; Calduch-Giner, J.-A.; Kaushik, S.; Pérez-Sánchez, J. Combined replacement of fish meal and oil in practical diets for fast growing juveniles of gilthead sea bream (Sparus aurata L.): Networking of systemic and local components of GH/IGF axis. Aquaculture 2007, 267, 199-212. [CrossRef]

4. NRC (National Research Council). Nutrient Requirements of Fish and Shrimp; National Academy Press: Washington, DC, USA, 2011.

5. Domínguez, D.; Rimoldi, S.; Robaina, L.; Torrecillas, S.; Terova, G.; Zamorano, M.J.; Karalazos, V.; Hamre, K.; Izquierdo, M. Inorganic, organic, and encapsulated minerals in vegetable meals-based diets for Sparus aurata (Linnaeus, 1758). PeerJ 2017, 5, e3710. [CrossRef] [PubMed]

6. Kaushik, S. Use of alternative protein sources for the intensive rearing of carnivorous fishes. In Mediterranean Aquaculture; Flos, R., Tort, L., Torres, P., Eds.; Ellis Horwood: Chinchester, UK, 1990; pp. 125-138.

7. Krogdahl, A.; Penn, M.; Thorsen, J.; Refstie, S.; Bakke, A.M. Important antinutrients in plant feedstuffs for aquaculture: An update on recent findings regarding responses in salmonids. Aquac. Res. 2010, 41, 333-344. [CrossRef] 
8. Hansen, A.C.; Hemre, G.I. Effects of replacing fish meal and oil with plant resources in on-growing diets for Atlantic cod Gadus morhua L. Aquac. Nutr. 2013, 19, 641-650. [CrossRef]

9. Torrecillas, S.; Mompel, D.; Caballero, M.J.; Montero, D.; Merrifield, D.; Rodiles, A.; Robaina, L.; Zamorano, M.; Karalazos, V.; Kaushik, S.; et al. Effect of fishmeal and fish oil replacement by vegetable meals and oils on gut health of European sea bass (Dicentrarchus labrax). Aquaculture 2017, 468, 386-398. [CrossRef]

10. Pittman, K.; Sourd, P.; Ravnøy, B.; Espeland, Ø.; Fiksdal, I.U.; Oen, T.; Pittman, A.; Redmond, K.; Sweetman, J. Novel method for quantifying salmonid mucous cells. J. Fish Dis. 2011, 34, 931-936. [CrossRef] [PubMed]

11. Gómez, D.; Sunyer, J.O.; Salinas, I. The mucosal immune system of fish: The evolution of tolerating commensals while fighting pathogens. Fish Shellfish Immunol. 2013, 35, 1729-1739. [CrossRef] [PubMed]

12. Ellis, A.E. Innate host defense mechanisms of fish against viruses and bacteria. Dev. Comp. Immunol. 2001, 25, 827-839. [CrossRef]

13. Guardiola, F.A.; Cuesta, A.; Arizcun, M.; Meseguer, J.; Esteban, M.A. Comparative skin mucus and serum humoral defence mechanisms in the teleost gilthead seabream (Sparus aurata). Aquaculture 2014, 36, 545-551. [CrossRef] [PubMed]

14. Roberts, S.D.; Powell, M.D. The viscosity and glycoprotein biochemistry of salmonid mucus varies with species, salinity and the presence of amoebic gill disease. J. Comp. Physiol. B 2005, 175, 1-11. [CrossRef] [PubMed]

15. Van Der Marel, M.; Caspari, N.; Neuhaus, H.; Meyer, W.; Enss, M.-L.; Steinhagen, D. Changes in skin mucus of common carp, Cyprinus carpio L., after exposure to water with a high bacterial load. J. Fish Dis. 2010, 33, 431-439. [CrossRef] [PubMed]

16. Estensoro, I.; Jung-Schroers, V.; Alvarez-Pellitero, P.; Steinhagen, D.; Sitjà-Bobadilla, A. Effects of Enteromyxum leei (Myxozoa) infection on gilthead sea bream (Sparus aurata) (Teleostei) intestinal mucus: Glycoprotein profile and bacterial adhesion. Parasitol. Res. 2013, 112, 567-576. [CrossRef] [PubMed]

17. De Luca, C.; Valacchi, G. Surface Lipids as Multifunctional Mediators of Skin Responses to Environmental Stimuli. Mediat. Inflamm. 2010, 3, 321494. [CrossRef] [PubMed]

18. Brinchmann, M.F. Immune relevant molecules identified in the skin mucus of fish using -omics technologies. Mol. BioSyst. 2016. [CrossRef] [PubMed]

19. Braun, A.; Treede, I.; Gotthardt, D.; Tieje, A.; Zahn, A.; Ruhwald, R.; Schoenfeld, U.; Welsh, T.; Kienle, P.; Erben, G.; et al. AÑterations on phospholipid concentration and species composition of the intestinal mucus barrier in ulcerative colitis: A clue to pathogenesis. Inflamm. Bowel Dis. 2009, 15, 1705-1720. [CrossRef] [PubMed]

20. Hussin, N.M.; Shaarani, S.M.; Sulaiman, M.R.; Ahmad, A.H.; Vairappan, C.S. Chemical composition and antioxidant activities of catfish epidermal mucus. JOAAT 2017, 4, 73-77. [CrossRef]

21. Sato, S.; Hirayama, T.; Hirazawa, N. Lipid content and fatty acid composition of the monogenean Neobenedenia girellae and comparison between the parasite and host fish species. Parasitology 2008, 135, 967-975. [CrossRef] [PubMed]

22. Lichtenberger, L.M. The hydrophobic barrier properties of gastrointestinal mucus. Annu. Rev. Physiol. 1995, 57, 565-583. [CrossRef] [PubMed]

23. Hills, B.A. Surface-acting phospholipid: A Pandora's box of clinical applications. Part I. The lung and air spaces. Int. Med. J. 2002, 32, 170-178. [CrossRef]

24. Gibson, P.R.; Muir, J.C. Reinforcing the mucus: A new therapeutic approach for ulcerative colitis? Gut 2005, 54, 900-903. [CrossRef] [PubMed]

25. Ab Rahman, M.; Asrhad, R.; Shaharom, F.; Ariffin, N.A. Amino Acid and Fatty Acid Profile in Epidermal Mucus of Bluestreak Cleaner Wrasse (Labroides dimidiatus): Possible Role as Defense Mechanism against Pathogens. J. Life Sci. 2012, 6, 1371-1377.

26. Jais, A.M.M.; Matori, M.; Kittakoop, P.; Sowanborirux, K. Fatty Acid Compositions in Mucus and Roe of Haruan, Channa Striatus, for Wound Healing. Gen. Pharm. 1998, 30, 561-563. [CrossRef]

27. Ehehalt, R.; Wagenblast, J.; Erben, G.; Lehmann, W.; Hinz, U.; Merle, U.; Stremmel, W. Phosphatidylcholine and lysophosphatidylcholine in intestinal mucus of ulcerative colitis patients. A quantitative approach by nanoelectrospray tandem mass spectrometry. Scand. J. Gastroenterol. 2004, 39, 737-742. [CrossRef] [PubMed]

28. Izquierdo, M.S.; Obach, A.; Arantzamendi, L.; Montero, D.; Robaina, L.; Rosenlund, G. Dietary lipid sources for seabream and European seabass: Growth performance, tissue composition and flesh quality. Aquac. Nutri. 2003, 9, 397-407. [CrossRef] 
29. Folch, J.; Lees, M.; Sloane-Stanley, G.H. A simple method for the isolation and purification of total lipids from animal tissues. J. Biol. Chem. 1957, 226, 497-509. [PubMed]

30. Juaneda, P.; Rocquein, G. Rapid and convenient separation of phospholipids and non-phosphorous lipids from rat heart using silica cartridges. Lipids 1985, 20, 40-41. [CrossRef] [PubMed]

31. Christie, W.W. Lipid Analysis, 2nd ed.; Pergamon Press: Oxford, UK, 1982; p. 201.

32. Izquierdo, M.; Arakawa, T.; Takeuchi, T.; Haroun, R.; Watanabe, T.; Izquierdo, M. Effect of n-3 HUFA levels in Artemia on growth of larval japanese flounder (Paralichthys olivaceous). Aquaculture 1992, 105, 73-82. [CrossRef]

(C) 2019 by the authors. Licensee MDPI, Basel, Switzerland. This article is an open access article distributed under the terms and conditions of the Creative Commons Attribution (CC BY) license (http:/ / creativecommons.org/licenses/by/4.0/). 